\title{
O REGIME DE COLABORAÇÃO E O ENSINO MÉDIO: UMA ANÁLISE DE CONTEXTO*
}

\author{
MARIA CiavatTA ${ }^{* *}$
}

A primeira norma é a da contextualização que consiste em colocar um evento ou uma ideia em sua época, em um quadro social, em um ambiente intelectual e linguístico, na paisagem mental ao qual pertence. (TRAVERSO, 2012, p. 17)

\begin{abstract}
RESUMO: Por contexto entendemos o conjunto de relações históricas que se estabelecem em torno de um fenômeno ou objeto de estudo. A LDB (Lei n. 9.394/96) é explicita, mas sucinta sobre o regime de colaboração (art. $8^{\circ}$ ). Em primeiro lugar, tratamos da questão da sociedade brasileira e a educação, onde destacamos três aspectos: a desigualdade socioeconômica, a privatização da educação, a qualidade da escola pública e o empresariamento da educação. Partimos de dois pressupostos: a democracia participativa e a distinção entre o público e o privado, e buscamos refletir sobre o significado do regime de colaboração, destacando o financiamento da educação e a autonomia escolar e docente.
\end{abstract}

Palavras-chave: Contexto. Regime de colaboração. LDB.

\section{Collaborative PARTNERSHIPS AND SECONDARY EDUCATION:}

\section{A CONTEXT ANALYSIS}

ABSTRACT: By context we mean the set of historical relations that are established around a phenomenon or object of study. The LDB (Law n. 9.394/96) is explicit but succinct about Collaboration (art. 8). First, we address the question of Brazilian society and education, where we highlight three aspects: the socioeconomic inequality, the privatization of education, the quality of public education and entrepreneurship. We start with two assumptions: participatory democracy and the distinction between public and private, and we reflect on the meaning of Collaboration, highlighting education funding and the autonomy of schools and teachers.

Key words: Context. Collaborative partnerships. LDB.

\footnotetext{
* $\quad$ Este texto tem por base o debate desenvolvido na sessão temática "Ensino Médio, Regime de Colaboração e Sistema Nacional de Educação", realizado durante o IV Seminário Brasileiro de Educação (IV SEB), promovido pelo Centro de Estudos Educação e Sociedade (Cedes) na Universidade Estadual de Campinas (Unicamp), nos dias 21 a 23 de fevereiro de 2013.

** Programa de Pós-Graduação em Educação da Universidade Federal Fluminense (UFF). Niterói (RJ) - Brasil.

Contato com a autora: <mciavatta@terra.com.br>
} 


\section{LA REGLE DE COLLABORATION ET L'ENSEIGNEMENT SECONDAIRE:} UNE ANALYSE DU CONTEXTE

RÉSUMÉ: Comme contexte, nous comprenons l'ensemble des relations historiques qui sont établies autour d'un phénomène ou d'un objet d'étude. La LDB (Loi n. 9394/96) est explicite mais succincte sur la Règle de Collaboration (art. 8). Premièrement, nous abordons la question de la société brésilienne et de l'éducation, dans ce sujet nous détachons trois aspects: l'inégalité socioéconomique, la privatisation de l'éducation, la qualité de l'enseignement public et de l'entrepreneuriat. Nous partons de deux préssuposés: la démocratie participative et la distinction entre public et privé, et nous réfléchissons à la signification de la régle de collaboraction en soulignant le financement de l'éducation et l'autonomie des écoles et des enseignants.

Mots-clés: Contexte. Système de contribution. LDB.

\section{Introdução}

$\mathrm{A}$

LDB (Lei n. 9394/96) é explicita, mas sucinta sobre o regime de colaboração: "A União, os Estados, o Distrito Federal e os Municípios organizarão, em regime de colaboração, os respectivos sistemas de ensino" (art. 8o., grifos nossos). Seguem-se as atribuições das três instâncias citadas. Alguns interpretam que já estaria dada a regulamentação do regime de colaboração, mas a realidade de sua implementação, na sociedade desigual e diferenciada que somos, mostra que a questão não é tão simples.

Neste artigo, buscamos compreender alguns aspectos do contexto do regime de colaboração previsto nos termos da lei. Procuramos situá-lo como parte integrante das condições socioeconômicas, políticas e culturais que tomam forma na sociedade brasileira e em alguns aspectos da educação e, de modo particular, no ensino médio.

Por "contexto" entendemos o conjunto de relações sociais que se estabelecem em torno de um fenômeno ou objeto de estudo e que se constituem em suas múltiplas determinações históricas. O exemplo clássico deste tipo de análise é dado através do termo população, o qual, à primeira vista, é uma noção geral que designa todos os conjuntos de seres de uma determinada área geográfica ou contexto social, tais como: população trabalhadora, população estudantil, brasileira, entre outras. Contudo, para conhecer cada uma dessas populações na sua particularidade, precisamos conhecer as relações sociais que as definem. No caso da população trabalhadora, seriam as relações de trabalho, moradia, salário, direitos laborais, entre outras (MARX, 1977).

No caso do regime de colaboração, seu significado deve ser buscado nos fatos e fenômenos do contexto da promulgação da lei e com as condições de sua realização na educação. Em primeiro lugar, tratamos da questão da sociedade brasileira e 
a educação, onde se destacam três aspectos: a desigualdade socioeconômica, a privatização da educação, a qualidade da escola pública e o empresariamento da educação. Partimos de dois pressupostos: a democracia participativa e a distinção entre o público e o privado. A seguir, buscamos refletir sobre o significado do regime de colaboração previsto na lei, destacando o financiamento da educação e a autonomia escolar e docente. ${ }^{1}$

\section{A sociedade brasileira - impasses na lei e na educação}

O Brasil está há mais de dois anos sem um Plano Nacional de Educação (PNE) em vigência, já que o anterior cobria os anos de 2000 a 2010. O Projeto de Lei n. 8.035, para o PNE 2011-2020, ficou 18 meses em tramitação, tendo sido aprovado na Câmara dos Deputados no último mês de junho de 2012, estando agora em discussão no Senado Federal. Qual sua importância para o bom andamento de uma educação pública de qualidade no país?

Aparentemente, pouca ou nenhuma, já que as escolas continuaram funcionando; setores organizados dos educadores continuaram a questionar as condições de trabalho e de estrutura das escolas; o analfabetismo continua não "erradicado"; a universalização do ensino médio não se realizou nos termos da lei; há avanços significativos dos setores privados recebendo recursos públicos em nome da melhoria empresarial da educação (a exemplo do Programa Nacional de Acesso ao Ensino Técnico e Emprego - Pronatec - e a contratação de entidades privadas, como o "Sistema $S^{\prime \prime}$, para atuar nos cursos de educação profissional). Mas o fato da vida e da educação seguirem seu curso não significa que o PNE seja dispensável, nem que os problemas estejam resolvidos. Apenas é adiada a decisão sobre alguns sérios problemas sociais e educacionais.

Com estas interrogações iniciais e com a inconformidade que o tema requer, vamos examinar alguns aspectos da sociedade brasileira que ajudam a decifrar o aparente descaso com o PNE que, entre outras coisas, deve definir o montante de recursos que a União investirá em educação, como serão divididos entre a União, os estados e os municípios, determinando o padrão de investimentos e a qualidade da educação pública, inclusive do ensino médio.

O regime de colaboração assegurado pela Constituição Federal de 1988, artigo 23 (modificada pela Emenda Constitucional n. 53 de 2006), define competências comuns à União, aos estados e municípios para proporcionar "meios de acesso á cultura, à educação e à ciência". No que se refere à educação, o artigo constitucional 206 reitera "a igualdade de acesso e permanência na escola" (inciso I) e a garantia do padrão de qualidade do ensino a ser oferecido (inciso VII) (FERRETTI, 2012, p. 1). 
Seria o regime de colaboração a garantia do Sistema Nacional de Educação, considerando a desigualdade social e econômica do país e as diferenças entre Estados e entre municípios? No entanto, como destaca a Conferência Nacional da Educação (Conae), no Eixo I, e diversos estudos, a ausência de regulamentação do regime de colaboração não conduz à articulação prevista (idem, ibid.).

Estamos tratando de problemas do presente. Segundo renomados historiadores, é no presente que se buscam as questões sobre as quais a história do passado tem algo a dizer (BLOCH, 2001). E não é desprovida de interrogação a ausência de um Plano Nacional de Educação, a dificuldade de conceituar e de levar à ação um Sistema Nacional de Educação e o regime de colaboração.

Chama atenção como, historicamente, o Brasil registra a secundarização da educação básica (infantil, fundamental e média) de toda a população (FERRETTI, op. cit.). Isso tem se dado, basicamente, pela ausência de políticas de universalização da educação; pelo contraponto da educação privada para as classes médias e altas; e pela presença dos empresários defendendo a formação imediata para o trabalho para as classes trabalhadoras, em detrimento da qualidade da educação geral de adolescentes, jovens e adultos.

\section{A desigualdade social e econômica}

Revendo Fernandes (1981), Carone (1978) e Albuquerque (1981), encontramos alguns elementos históricos de sua gênese na constituição do capitalismo e da organização jurídica e política do país. São aspectos reconhecidos nas pessoas que habitam as cidades e os campos, em regiões, localidades, bairros e ruas das áreas da periferia empobrecida e do interior rural do país, nos jovens que abandonam o ensino médio.

Para Fernandes (op. cit., p. 150), sua gênese está nas "estruturas econômicas, sociais e políticas da sociedade colonial [que] não só moldaram a sociedade nacional subsequente: determinaram a curto e a longo prazos as proporções e o alcance dos dinamismos coloniais absorvidos do mercado mundial". Houve uma rápida adaptação aos "negócios de exportação e de importação controlados economicamente por um centro hegemônico externo, mas dirigido politicamente a partir de dentro".

Trata-se de uma distribuição de renda e de serviços (educação, saúde, saneamento, previdência, segurança) com disparidades inaceitáveis, se houvesse o objetivo coerente de dar um padrão de vida digno para a população. São os limites dados pelo capitalismo que parece samba, "agoniza, mas não morre". ${ }^{2}$ Sobrevive da produção destrutiva da natureza e dos meios de vida que servem à sobrevivência e à humanização, nas crises sucessivas da acumulação "desmedida do capital" (LINHART, 2007). 
Na análise de Fernandes (op. cit., p. 18), vivemos uma situação histórica de imperialismo total, cujos traços mais marcantes se fazem presentes na vida social:

[...] ele organiza a dominação externa a partir de dentro e em todos os níveis da ordem social, desde o controle da natalidade, a comunicação de massa e o consumo de massa, até a educação, a transplantação maciça de tecnologia ou de instituições sociais, a modernização da infra e da superestrutura, os expedientes financeiros ou do capital, o eixo vital da política nacional etc. Segundo, esse tipo de imperialismo demonstra que mesmo os mais avançados países latino-americanos ressentem-se da falta dos requisitos básicos para o rápido crescimento econômico, cultural e social em bases autônomas.

Em termos breves, esta é a gênese do capitalismo dependente, da ordem social competitiva que se implantou no país e da sociedade de classes extremamente diferenciada, em que se organiza a sociedade brasileira, e que ajudam a compreender a natureza e a qualidade dos serviços públicos oferecidos à população. Se a emancipação nacional no início século XIX (1822) foi uma revolução política - embora incompleta, porque ela manteve o país atado ao poder imperial do colonizador até a Proclamação da República (1889) -, ela não se fez acompanhar de uma revolução econômica e social que incorporasse toda a população em termos de cidadania plena, nem mesmo com a República.

Contudo, esse fato fundamental estruturante, que ajuda a compreender a dificuldade de implantar uma distribuição de renda e de serviços sociais, igualitária e equitativa, incute-nos o sentimento ético e político da obrigação de compreender e atuar sobre as mediações desse processo no presente.

\section{A privatização da educação}

A presença da Igreja Católica e dos liberais, irmanados em defesa de seus interesses particulares na educação, constituiu a liderança do individualismo e da privatização da educação nas lutas da Lei de Diretrizes e Bases da Educação Nacional (LDBEN, Lei n. 4.024/61). O argumento da liberdade da família na escolha da educação a ser dada a seus filhos desafiou o ideário republicano de um sistema público de ensino leigo.

As aberturas e isenções obtidas no período ampliaram-se durante a ditadura pela expansão do ensino de $2^{\underline{o}}$ grau (hoje ensino médio) e do ensino superior. Geraram, com o tempo, as grandes instituições privadas que temos hoje, não apenas algumas tradicionais e respeitadas instituições confessionais, mas a grandes empresas de ensino, muitas em processo de associação com conglomerados privados dos Estados Unidos e da Europa.

Outro aspecto desse contexto preocupante é a privatização dos serviços através das entidades do "terceiro setor", que prestam serviços de iniciativa própria 
e sob demanda dos estados e municípios. ${ }^{3}$ No senso comum, a partir dos anos de 1980, as entidades em efetivo regime de colaboração são as Organizações Não Governamentais (ONGs) e, nos anos de 1990, as Organizações da Sociedade Civil de Interesse Público (Oscips).

As ONGs se iniciarem com os movimentos da sociedade civil, organizados em defesa de serviços para a população e em oposição à última década do regime militar. Atualmente, são entidades que podem gozar de isenção tributária, quando caracterizadas como sem fins lucrativos e, como entidades privadas, prestam serviços, organizam ações junto à população, com recursos públicos e privados.

As Oscips se dedicam a parcerias e convênios em todos os níveis de governo e órgãos públicos (federal, estadual, municipal). Ambas têm sido alvo de críticas pela disputa privada de recursos públicos, atribuindo-se funções públicas no exercício do assistencialismo, da solidariedade, da filantropia, do voluntariado, de ações comunitárias, secundarizando a luta por direitos junto ao Estado.

\section{A qualidade da escola pública}

Em um processo amplamente registrado nos estudos acadêmicos, com a chegada da massa populacional à escola pública, distante da cultura das elites, e da redução dos investimentos em educação a partir do golpe civil-militar de 1964, facilmente se ideologizou todo o processo. Passou-se a atribuir ao nível familiar, à escola pública e aos professores a baixa qualidade do ensino, as repetências e abandono escolares, a defasagem idade/série.

Seu efeito agravou-se com as aspirações do Governo F. H. Cardoso para o Brasil galgar posições comparáveis aos países desenvolvidos na hierarquia das estatísticas internacionais sobre escolarização da população. Com diferentes processos de avaliação, facilitou-se a promoção no ensino fundamental e o Brasil passou de cerca de $70 \%$ a $94 \%$ das crianças e jovens na escola na idade prevista, índice semelhante ao daqueles países.

Como consequência, observa-se que, sem a avaliação real do processo ensinoaprendizagem, tirou-se a autoridade do conhecimento dos professores junto aos alunos, e o respeito por parte das famílias. Com a sistematização dos exames de avaliação do rendimento escolar a partir do final dos anos de 1980 e, principalmente, depois de 1995, em paralelo, diante dos resultados insatisfatórios, o professor passou a ser responsabilizado pelo baixo nível obtido. Por último, em alguns estados (a exemplo de São Paulo e Rio de Janeiro) foram instituídos os bônus aos professores e a toda a escola para a aprovação de um determinado percentual de alunos (CIAVATTA, 2012). 
Com o final do Governo F. H. Cardoso, retificou-se a rota da, assim chamada, "promoção automática", mas não se refez a qualidade de um sistema deficiente em vários aspectos. São problemas de qualidade da educação oferecida e da capacidade de crianças, jovens e suas famílias absorverem a oportunidade de escolarização que lhes é dada.

A escola e a educação oferecidas não são objetos isolados que têm efeito educativo independente dos sujeitos dos serviços oferecidos. A educação é uma relação, um objeto relacionado a outros tantos e aos sujeitos envolvidos. Quem são os sujeitos, na linguagem neoliberal, os usuários principais dos serviços públicos educacionais? São as famílias, muitas das quais com várias carências: moram mal, em casas improvisadas ou carentes dos serviços básicos, moram distante, têm emprego de baixa remuneração ou estão nas atividades informais. A família como um todo, e não apenas a escola, necessita de outra qualidade.

Assim entramos em uma questão correlata "imexível" nesta sociedade que cultiva e disfarça a desigualdade entre as classes sociais, com o apoio decisivo dos meios de comunicação. Estes edulcoram a miséria com os efeitos de demonstração de artistas e atletas colhidos entre milhares que ficam para trás, já que as oportunidades da fama (notoriedade, publicidade, celebridade, excelência) são, necessariamente, restritas.

Merece também destaque a crítica que Ferretti (2012, p. 7) faz ao uso do Exame Nacional do Ensino Médio (Enem): “como mecanismo de regulação e controle das escolas por meio de sua hierarquização, o que tende a desencadear mecanismos perversos de manipulação e conformação do trabalho docente".

\section{O empresariamento da educação}

Em linhas gerais, a produção cresceu em complexidade técnica e social, mesmo para algumas funções mais simples. No entanto, o próprio governo impulsiona a educação profissional aligeirada, em detrimento de um programa efetivo de universalização da educação básica. Programas com a promessa da inserção imediata no mercado de trabalho, como o Pronatec, abrem mão não apenas no ensino médio, do domínio efetivo dos conhecimentos adequados às exigências do mundo atual, de uma leitura fundamentada dos problemas vividos pelos jovens hoje.

Desde os anos de 1930, setores empresariais empenhados na formação da mão de obra para a indústria pautaram, junto ao governo federal, no interior do MEC, o tipo de educação profissional que devia ser oferecido aos operários e a seus filhos (entre outros, ver FONSECA, 1986). A história registra a separação entre o ensino secundário propedêutico da formação profissional até o final da década de 1950. As Leis de Equivalência (1950, 1953 e 1959) e, finalmente, a LDBEN (1961) deram plena 
equivalência de acesso ao ensino propedêutico e ao ensino superior aos portadores de diploma de ensino profissional e técnico.

Durante a ditadura civil-militar, a profissionalização compulsória (Lei n. 5.692/71, que vigorou até 1982) simulou um projeto societário igualitário que se desvaneceu diante da imposição da preparação de todos para o trabalho. Mas para os jovens oriundos das classes altas e médias prevaleceu a preparação para a entrada na universidade. No âmbito das escolas públicas, faltaram recursos e vontade política de equipar as escolas com laboratórios, oficinas e ateliês para realizar com qualidade a profissionalização prevista na lei.

Nos anos de 1990, o Governo F. H. Cardoso preteriu os termos da LDB (Lei n. 9.394/96), recém-aprovada, e decretou a separação entre o ensino médio e a educação profissional, reduzida a seus mecanismos operacionais para a formação inicial e continuada dos trabalhadores (PLANFOR / MTE) e para os estudantes do ensino médio de nível técnico (Decreto n. 2.208/97).

Mais recentemente, apesar de revogados os termos do referido Decreto (pelo Decreto n. 5.154/04, incorporado à LDB pela Lei n. 11.741/08), o CNE foi apoiado pela Confederação Nacional da Indústria (CNI) e o Sistema S, contrariando a proposta alternativa do movimento organizado de pesquisadores e entidades representativas da sociedade civil. Não obstante mais de dois anos de contestação e propostas com base no ideário da educação politécnica de da formação integrada, o CNE aprovou as DCN EPT com a maquiagem do trabalho como princípio educativo e os conteúdos da doutrina das competências através do símbolo "Chave": Conhecimentos, Habilidades, Atitudes, Valores e Emoções (CIAVATTA; RAMOS, 2012).

No âmbito mais amplo da educação, os empresários pontificam como assessores privilegiados do governo - através do Pronatec, do movimento "Todos pela Educação", das empresas de prestação de serviços que se sustentam nos diversos sistemas de avaliação implantados no país, sob a inspiração dos organismos internacionais, como a OCDE (FREITAS, 2012; MORAES; FERRETTI, 2011) - o “Conviva Educação", um sistema virtual "gratuito", desenvolvido por grandes empresários, “investidores sociais" (FRIGOTTO, 2013, p. 28).

\section{Pressupostos: democracia participativa e distinção entre o público e o privado}

A sociedade desigual, a privatização da educação, a qualidade da educação pública e o empresariamento da educação constituem os aspectos de contexto que se destacam para o entendimento de como se desenvolvem as ações relativas ao PNE, ao Sistema Nacional de Educação e ao regime de colaboração. Dois pressupostos de 
vida social e política embasam a análise que fazemos: a democracia participativa e a distinção entre o público e o privado.

\section{A democracia participativa}

Um passado de quase três décadas de vida em um regime de ditadura nos deu a convicção de que a democracia não é um fim, mas um caminho a ser aperfeiçoado para se avançar social e politicamente no país. O tema nos obriga a pensar o que entendemos por democracia, qual sua origem histórica e quais as condições atuais de sua realização no Brasil.

O eixo norteador de ambas as questões deve ser a questão do trabalho, pela posição estruturante que a atividade produtiva ocupa na organização da sociedade, da cultura e da educação, no ensino médio e na educação profissional. Incluem-se aí o papel do Estado numa sociedade dominada pelas exigências da acumulação capitalista internacionalizada e a especificidade da democracia no Brasil, sob a hegemonia neoliberal e a tradição do Estado autoritário e centralizador.

Como outros países latino-americanos, somos sociedades parcialmente modernas, altamente dependentes e atravessadas por elementos autoritários profundamente enraizados na vida social. Estes são fenômenos que se articulam e se combinam de modo heterogêneo em cada caso. A importação de modelos de interpretação homogeneízam as potencialidades de cada país, desprendendo-as de sua especificidade histórica (NUN, 1987).

Historicamente, a variação de formas de governo não é gratuita, prende-se aos diversos títulos que os homens têm para "comandar": força, riqueza, talento, experiência. Prende-se também, particularmente, no caso da democracia, às condições institucionais de discussão, de confronto público da palavra e das ideias que são expressão de interesses gerais ou particulares.

O que queremos destacar, com estas breves considerações, é que, tanto na civilização grega, de onde extraímos o primeiro modelo de democracia, como no mundo moderno, a concepção e a prática política, a nós legadas, foram fruto das forças materiais e culturais então existentes. A contribuição fundamental da filosofia da práxis à ciência da política e da história "é a demonstração de que não existe uma natureza humana abstrata, fixa e imutável (conceito derivado do pensamento religioso), mas que a natureza humana é o conjunto das relações sociais historicamente determinadas" (MARX; ENGELS, 1979; especialmente, a VI Tese sobre Feuerbach).

Do exposto podemos derivar algumas ideias básicas para a compreensão da democracia: (i) quaisquer que sejam os valores norteadores de uma sociedade e as formas de governo assumidas por sua organização política, eles têm por base uma 
sociedade concreta; (ii) as estruturas de legitimação de uma sociedade, o pensamento político, as formas ideológicas, com que se apresentam as formas de governo, são sempre mais aparentes que as condições de base (as relações sociais de produção) em que se fundamentam ou que lhes dão origem; (iii) a forma de organização política mais avançada que conhecemos, a democracia, é a forma mais frágil, exatamente porque supõe a expressão das condições concretas, contraditórias da vida social, dos interesses de grupos e classes sociais; (iv) a democracia não é um conceito de igualdade universal (como faz crer a doutrina política liberal), mas de desigualdade real, que é administrada segundo parâmetros que podem ser mais ou menos igualitários.

Na sua forma histórica - como organização política -, talvez a mais perfeita, a democracia grega pôde ser tão discriminadora como eram as condições reais de existência da sociedade grega, onde havia escravos, homens livres, estrangeiros e senhores, e só os últimos gozavam de plenos direitos de cidadania. A memória da sociedade brasileira mostra-nos que todos esses elementos estão presentes em nossa história (CIAVATTA, 2002).

Vivemos em uma democracia representativa que é uma condição necessária, mas não suficiente para resolver os problemas que enfrentamos. Embora não tenhamos vivência e suficiente clareza no conhecimento dos mecanismos institucionais que conduzam à democracia participativa nas diversas instâncias da vida social, ela é uma aspiração e um caminho delineado por alguns grupos sociais e políticos.

No Brasil, ainda é muito forte a presença das classes sociais hegemônicas conduzindo as decisões jurídico-legais pelo poder centralizado, operando com a descentralização na execução, a exemplo das formas de financiamento da educação, dos programas de governo sobre problemas magnos da sociedade, da autoridade limitante da autonomia dos professores em sala de aula - fenômenos em crescimento nas últimas décadas. Está em curso uma nova onda conservadora ao arrepio das aspirações democráticas?

\section{A distinção entre o público e o privado}

O segundo pressuposto de nossa reflexão é a distinção entre público e privado no tratamento da coisa pública. Na origem latina, o termo res pubblica significa coisa do povo e deu origem ao termo república, o Estado republicano, que é atribuído a uma forma de governo em que um ou mais são eleitos para representar os demais. Hegel apresenta o Estado como "a materialização do interesse geral da sociedade" e estaria acima dos interesses sociais.

O Estado seria capaz de superar a divisão entre ele próprio e a sociedade civil [econômica no sentido hegeliano], bem como o abismo entre o indivíduo como pessoa privada 
e o cidadão. Marx rejeita tais pretensões em sua Crítica da filosofia do direito de Hegel sob a alegação de que o Estado, na vida real, não representa o interesse geral, mas antes, defende os interesses da propriedade. (apud BOTTOMORE, 1988, p. 134)

Sem poder entrar na discussão do conceito de Estado em sua complexidade nas diversas vertentes da ciência política, apenas sinalizamos alguns aspectos de interesse para a questão. Na sociedade liberal capitalista em que vivemos, prevalece a compreensão do Estado como o representante de todos, aquele que dispõe da coisa pública para o bem geral. Mas também fica evidente como classes e grupos sociais são beneficiários do poder do Estado em detrimento dos demais, a exemplo do agronegócio, da hegemonia empresarial na educação profissional de nível médio.

A questão da necessidade da distinção entre público e privado advém deste e de outros aspectos da vida prática. Há uma ideia bastante confusa sobre público e privado que não distingue as ações do Estado e da sociedade civil. O Estado é a instância máxima de representação do coletivo e suas ações tratariam da coisa pública, daquilo que se destina a todos - é o sentido idealista, criticado por Marx e Engels (1998).

A sociedade civil, no sentido gramsciano, como parte do Estado, assim como a sociedade política, seria constituída pelos representados e suas instituições ou entidades, aparelhos privados de hegemonia, que também tratariam do que se destina a todos. Temos por hipótese que daí advém a reivindicação das diversas entidades que prestariam "serviços públicos" não estatais. Contudo, visivelmente, as entidades envolvidas, mesmo as mais sérias e coerentes com a prestação de serviços para o bem comum, são constituídas de forma jurídica e social privada. Não têm os recursos nem o poder de universalizar os benefícios nos termos das políticas públicas, que implicam a lei para a universalização da medida ou serviço, orçamento do poder constituído e garantia de continuidade.

Vivemos uma anomia na compreensão do que cabe ao Estado como recolhedor de impostos e autodenominado representante da sociedade, de modo especial, na partilha dos recursos provenientes da receita pública (impostos, taxações, entre outros). A história do país e da privatização da educação, como vimos anteriormente, permite compreender um pouco do complexo processo dessa pretensa ampliação do sentido do público.

\section{0 regime de colaboração e o ensino médio}

A questão do regime de colaboração diz respeito, basicamente, à centralização e descentralização dos poderes, União, estados e municípios, ou à autonomia relativa de cada um destes no trato com a coisa pública, neste caso, a educação. Não 
se trata apenas de uma questão educacional, mas de organização política do país, da institucionalização da democracia, do sistema federativo e suas oscilações para o poder centralizado, como presenciamos em diversas fases da República, sendo as mais recentes e ostensivas o Estado Novo (1937-1945) e a ditadura civil-militar (1964-1985).

A recuperação de alguns aspectos do contexto do regime de colaboração pode propiciar maior aproximação com as dificuldades de sua institucionalização: a herança social competitiva, o financiamento da educação e a autonomia escolar e docente.

\section{A herança social competitiva}

Tendo em mente nossa hipótese de que a ordem social competitiva da sociedade capitalista em que vivemos (FERNANDES, 1981) fundou-se sobre a herança da ordem social escravocrata e senhorial, centralizadora, buscar as bases do presente no passado é uma forma de não se distanciar do chão da realidade material e simbólica. $\mathrm{O}$ autor destaca três elementos fundamentais da gênese do capitalismo que estabelecem e consolidam um estilo competitivo de vida social: (i) as estruturas herdadas da ordem social escravocrata e senhorial, com suas "condições, tensões ou inconsistências", custaram a se abrir à ordem social competitiva; (ii) a emergência, a universalização e a consolidação da ordem social competitiva foram produzidas por processos econômicos e socioculturais; (iii) a ordem social competitiva sob o capitalismo tem características estruturais e funcionais (FERNANDES, op. cit.). É nesse quadro estruturante da sociedade que podem ser explicadas as nuanças fugidias do regime de colaboração estabelecido na Constituição Federal (art. 211) e na LDB (Lei n. 9.394/96, art. $8^{\circ}$ a $11^{\circ}$ ), mas de difícil implementação, na medida em que, entre outras coisas, mexe com poderes privilegiados na ordem atual.

O exame de alguns autores nos permite algum avanço na compreensão do fenômeno além de seus aspectos aparentes. Com adverte Ferretti (2012, p. 1): “[...] a ausência de regulamentação sobre tal regime não só dificulta a articulação entre os entes federados, como também produz distorções nas tentativas de colocar tal dispositivo em prática". Uma das incongruências apontadas pelo autor é a descentralização da execução, mas não das decisões e do controle dos recursos, na avaliação dos resultados.

Paulo Hentz (2009, p. 1) é incisivo ao analisar o Estado federativo e o regime de colaboração:

O Princípio Federativo não comporta relações hierárquicas entre esferas do poder político; está calcado na ideia da relação entre iguais. Assim, entre União, estados e municípios, não há relação de subordinação, por se constituírem entes federados com igual 
dignidade, mas a relação desejável e esperada é a de colaboração, posto que subordinação é característica entre desiguais, enquanto colaboração é feita entre iguais. O Brasil é um exemplo de Estado em cuja história o Princípio Federativo passa por um processo de consolidação, não imune a interrupções e retrocessos.

O mesmo autor faz uma breve recuperação histórica do caráter federativo do Estado brasileiro na Constituição de 1891 e seus retrocessos periódicos até a Constituição cidadã de 1988. Questiona se é possível consolidar um Sistema Nacional de Educação em um regime de colaboração, "o qual se costuma, no discurso oficial, adjetivar como articulado" (ibid., p. 3).

Outro aspecto é a permanência de reformas educacionais centralizadoras, como foram nos anos de 1990, não assimiladas inteiramente pelos sistemas educacionais. Tratando do ensino médio, Ferretti (2012) lembra que, na questão curricular, o ensino médio, a educação profissional e o (Proeja), ainda convivem as reformas produzidas naquele período. Observa-se a permanência dos professores mais no desenvolvimento de conteúdos do que das competências, apesar de toda imposição dos discursos, materiais didáticos, formação inicial e continuada, estratégias de convencimento, etc. Outro exemplo é a recente aprovação das Diretrizes Curriculares Nacionais para o Ensino Médio de Nível Técnico, que mostra o poder centralizador do Conselho Nacional de Educação (CNE/MEC). Não obstante a aparência, mantém-se o espírito da legislação dos anos de 1990, conduzindo a educação de nível médio à formação profissional aligeirada nos cursos breves, reiterando as reformas neoliberais do período (CIAVATTA; RAMOS, 2012).

Falando sobre as diferenças entre a União, estados e municípios, Hentz (op. cit., p. 3) adverte que:

A fragilidade dos sistemas municipais (ou de muitos deles) não pode servir de argumento para que os sistemas estaduais os subordinem, voltando a uma realidade pré1988. Se estas fragilidades existem, podem os sistemas estaduais cooperar para seu fortalecimento através de colaboração com a entidade que representa aqueles sistemas em sua unidade federada. Se fragilidades há em alguns sistemas estaduais, é possível afirmar com plena convicção e tranquilidade que não é com sua submissão que se lhe dará competência. (op. cit.).

\section{0 financiamento da educação}

Outro aspecto a levar em conta é a distribuição de recursos financeiros e sua utilização. Com esta questão, voltamos ao problema das desigualdades sociais, da diferenciação entre os entes federados. Para Ferretti (op. cit.), não se trata apenas de uma distribuição de recursos, a questão atinge a vida das pessoas e das localidades onde vivem, sua capacidade pessoal e da coletividade de inserir-se 
no sistema. Recente matéria jornalística informa que "Desinformação e falta de estrutura em cidades mais pobres explicam falha no cadastro usado para pagar benefícios" dos diversos programas sociais implementados pelo governo" (MAGALHÃES, 2013). São dois milhões de pessoas "que vivem abaixo da linha de miséria". Destaque-se que este é um aspecto mais tangível em termos de demanda, porque há também a carência de recursos técnicos e administrativos dos municípios em fundões do país.

Considerando os municípios estruturados, com sistemas informatizados de administração e de ensino, a questão é mais inquietante do ponto de vista do regime de colaboração, para subordinação ou colaboração-autonomia para a consolidação democrática em todos os níveis de ação. Costa (2010, p. 106), estudando o financiamento à educação, especificamente o Programa Dinheiro Direto na Escola,

[...] trabalha com a hipótese de que, embora haja na legislação brasileira um discurso sobre a descentralização da gestão e a autonomia da escola, sua efetivação se depara com limites dados pela própria estrutura administrativa centralizada que organiza o sistema público de educação escolar estadual, configurando-se uma contradição.

Explicita essa contradição no fato de que o caráter federal do Estado pressupõe uma descentralização política, "mas o que prevalece nas redes escolares é a centralização, uma vez que as unidades escolares não têm estatuto de pessoa jurídica, sendo completamente dependentes das secretarias de educação" (idem, ibid.).

Estas são "órgãos compostos" reunindo outros órgãos menores, com atividades-fim idênticas, as unidades escolares; e outros órgãos menores com atividades-meio diversificadas, como os órgãos de pessoal, de material, de transportes, entre outros, "que auxiliam a realização do ensino, mas todos integrados e hierarquizados ao órgão maior" (MEIRELLES, 1985, apud COSTA, op. cit.).

Costa conclui que esse tipo de ingerência está normatizado no pacto federativo tal como prevê a Constituição, o que significa uma autonomia tutelada, que não é intervenção direta, mas a destinação acertada entre as escolas ou o conjunto de escolas e as secretarias. Através desses órgãos menores, as Unidades Executoras, as escolas são controladas porque submetidas às normas do governo central que distribui os recursos - no caso do programa examinado, o Fundo Nacional de Desenvolvimento da Educação (FNDE).

\section{A autonomia escolar e docente}

Por sua importância nas sociedades modernas, os conhecimentos auferidos na escola sempre foram objeto de avaliação, a começar dos tradicionais sistemas rígidos de provas escritas e orais. O que ocorre hoje é uma exacerbação do mecanismo 
avaliativo no mundo atual, com a finalidade de valor de mercado. Como objeto de avaliação, classificação e certificação, os conhecimentos e as instituições são submetidos a exames que, no caso dos melhores resultados, mesmo medindo raciocínio, reduzem o universo do conhecimento, expresso em informações e raciocínio, a mecanismos de acesso a posições no mercado (FREITAS, 2012).

A medida mais refinada desse processo de abastardamento da função docente é o bônus coletivo, que é distribuído a todo o conjunto dos trabalhadores da escola se todos se enquadrarem na política de aprovação de um percentual de alunos. ${ }^{4} \mathrm{Com}$ isso, as escolas e os governos vão para um ranking de status nacional e/ou internacional que, supostamente, mede o desenvolvimento dos países. Em países como o Brasil, são resultados abstraídos das condições de trabalho e de infraestrutura das escolas, das condições de vida dos alunos e dos professores, obtidos através do viés positivista dos fatos isolados de seu contexto.

Falando sobre as interfaces sobre pesquisa e políticas educativas, Claude Lessard (2011) expõe vários aspectos que, a nosso ver, têm a avaliação como expressão máxima da transposição da ideologia da competitividade para a definição e implementação das políticas educacionais. A escola tem sido alvo de disputas intensas, na medida em que se tornou um bem de mercado, e a avaliação tende a universalizar-se, como um instrumento do Estado regulador, de medição dos efeitos da política.

Através das agências internacionais, importamos modelos americanos e europeus "que medem a eficácia e a eficiências dos professores, dos programas, dos dispositivos, dos instrumentos e das práticas educativas". São modelos gerados na secretaria americana de educação, no International Association for the Evaluation of Internacional Achievement (IEA), na Organisation for Economic Cooperation and Development (OCDE), com uma matriz forte de ciência positivista, com base nos "estudos avaliativos quantitativos (se possível, longitudinais e multivariados) e os estudos experimentais ou quase experimentais" (op. cit., p. 61).

Outros fatos chamam atenção pela extravagância da medida do ponto de vista da autonomia escolar e docente. O secretário de Educação do estado do Rio de Janeiro tomou a decisão de "otimizar" os serviços educacionais através da "extinção de turmas de poucos alunos nas escolas de sua rede [...] classes que tenham menos de 20 alunos matriculados e remanejá-los dentro do colégio se for avaliado que a medida resultará num melhor aproveitamento de professores" (BERTA, 2013).

Sobre o mesmo fato, o relato de uma professora da rede estadual de educação do Rio de Janeiro mostra uma aparente perda do controle da evasão/abandono escolar dos alunos e uma ruptura com a possibilidade de compromisso dos professores. Para uma possível minoração do processo, o que se espera de uma escola é que estude as razões por que isso está ocorrendo e, se há professores disponíveis, organize 
os horários para projetos, atendimento aos alunos e outras iniciativas educacionais que possam minorar ou prevenir o fenômeno (BRUCE, 2012).

\section{Considerações finais}

O regime de colaboração que deve reger as políticas de financiamento propicia a autonomia e a gestão democrática da escola pública? Ou sustenta uma forma de intervenção com controle das verbas e redução dos gastos sociais? (COSTA, 2010). O que significa o regime de colaboração e de autonomia das unidades escolares diante do quadro descrito?

Procuramos nos aproximar do que pode ser chamado de verdade em relação ao regime de colaboração previsto na LDB, através de uma análise do contexto da sociedade brasileira em que a Lei tomou forma, mas não foi regulada para sua implementação. As escolas não são unidades técnicas, são sociais, relacionadas ao contexto em que atuam.

Embora o governo tenha aberto mão do discurso explícito da doutrina neoliberal - hoje atenuada em alguns aspectos, mas não revertida -, ainda mantém-se o Estado forte, o poder debilitado dos sindicatos, parcimônia nos gastos sociais, busca de estabilidade econômica, contenção da massa salarial, economia exportadora de matérias-primas e outras de baixo valor agregado, apoio ao agronegócio, entre outros.

O quadro delineado não anuncia solução fácil ou imediata. Há problemas estruturais da sociedade brasileira que mantêm os poderes centralizados em vários níveis e foros de decisão privilegiados. Mas a história existe como produção social da existência humana (MARX; ENGELS, 1979), nos termos da atuação política e organizativa dos sujeitos envolvidos. A regulamentação e a implementação da lei depende da correlação de forças em confronto.

A democracia participativa e a distinção entre público e privado são pressupostos de uma ação política de encaminhamento dos problemas no contexto de desigualdade socioeconômica, privatização da educação, qualidade da educação, entre outros fatores. Já teremos esgotado a força política dos movimentos sociais organizados?

\section{Notas}

1. Algumas propostas de ação foram apresentadas durante a sessão temática.

2. Verso do compositor carioca Nelson Sargento.

3. O primeiro setor seria o Estado, o segundo, o mercado e o terceiro, a sociedade civil, onde estariam as entidades não estatais e não mercantis. Montaño (2002, p. 182) critica o termo como "ideológico e não adequado ao real”, já que, na maioria das análises, não aparecem as organizações sindicais e 
os movimentos sociais combativos. É notável seu crescimento nos anos de 1990. Garrisson (2000) estimava em 5 mil o número de ONGs no Brasil.

4. Mínimo estipulado, sobre o qual não temos informações precisas.

\section{Referências}

ALBUQUERQUE, M.M. Pequena história da formação social brasileira. 2. ed. Rio de Janeiro: Graal, 1981.

BERTA, R. Turmas com menos de 20 alunos devem ser remanejadas. O Globo, Rio de Janeiro, 16 fev. 2013, p. 15.

BLOCH, M. Apologia da história ou O ofício do historiador. Rio de Janeiro: Zahar, 2001.

BOTTOMORE, T. (Org.). Dicionário do pensamento marxista. Rio de Janeiro: Zahar, 1988.

BRUCE, M. Entrevista gravada. Rio de Janeiro, 16 dez. 2011.

CARONE, E. A República Velha I: instituições e classes sociais (1889-1930). Rio de Janeiro; São Paulo: Difel, 1978.

CIAVATTA, M. A construção da democracia pós-ditadura militar: políticas e planos educacionais no Brasil. In: FÁVERO, O.; SEMERARO, G. (Org.). Democracia e construção do público no pensamento educacional brasileiro. Petrópolis: Vozes, 2002.

CIAVATTA, M.; RAMOS, M. A "era das diretrizes": a disputa pelo projeto de educação dos mais pobres. Revista Brasileira de Educação, Rio de Janeiro, v. 17, n. 49, p. 11-38, jan./abr. 2012.

COSTA, Á.C. O regime de colaboração entre União, estados e municípios no financiamento da educação no Brasil. Revista Brasileira de Política e Administração da Educação, Pernambuco, v. 26, n. 1, p. 105-121, jan./abr. 2010.

COSTA, M. Criar o público não estatal ou tornar o público estatal? In: ADRIÃO, T.; PERONI, V. O público e o privado na educação: interfaces entre o Estado e a sociedade. São Paulo: Xamã, 2005. p. 13-30.

FERNANDES, F. A revolução burguesa no Brasil: ensaio de interpretação sociológica. 3. ed. Rio de Janeiro: Zahar, 1981.

FERRETTI, C.J. O ensino médio e o regime de colaboração entre entes federados no Brasil. Trabalho apresentado no 4. Seminário de Educação Brasileira, Cedes/Unicamp, Campinas, 20 a 22 de fevereiro de 2012. (digital e impresso).

FONSECA, C.S. História do ensino industrial no Brasil. Rio de Janeiro: Senai/DN, 1986. 5 v.

FREITAS, L.C. Agenda dos reformadores empresariais pode destruir a educação 
pública no Brasil; entrevista a Michele da Costa. InformANDES, Brasília, DF, n. 16, p. 12-15, nov. 2012.

FRIGOTTO, G. Ensino médio e técnico profissional: disputa de concepções e precariedade. Le Monde Diplomatique Brasil, São Paulo, v. 6, n. 68, p. 28-29, mar. 2013.

GARRISON, J.W. Do confronto à colaboração: relações entre a sociedade civil, o governo e o Banco Mundial no Brasil. Washington, DC; Brasília, DF: Bird/BM, 2000.

HENTZ, P. O princípio federativo e o regime de colaboração. Trabalho apresentado na 32. Reunião Plenária do Forum dos Conselhos Estaduais de Educação, em 19 jun. 2009. Disponível em: <http://fnce.org/index.php?option=com_ content\&view=article\&id=54:o-principio-federativo-e-o-regime-de-colaboracao\&cat id=36:artigos\&Itemid=58>. Acesso em: 16 fev. 2013.

LESSARD, C. Pesquisa e políticas educativas: uma interface problemática. In: OLIVEIRA,D.A.; DUARTE, A. Políticas públicas e educação: regulação e conhecimento. Belo Horizonte: Fino Traço, 2011.

LINHART, D. A desmedida do capital. São Paulo: Boitempo, 2007.

MAGALHÃES, J.C. Governo vê 2,5 milhões miseráveis fora de programas sociais. Folha de S. Paulo, São Paulo, 16 fev. 2013. p. A4

MARX, K. Contribuição para a crítica da economia política. Lisboa: Estampa, 1983.

MARX, K.; ENGELS, F. A ideologia alemã. São Paulo: Ciências Humanas, 1979

MARX, K.; ENGELS, F. Manifesto do Partido Comunista. São Paulo: Cortez, 1998.

MONTAÑO, C. Terceiro setor e a questão social: crítica ao padrão emergente de intervenção social. São Paulo: Cortez, 2002.

MORAES, C.S.V.; FERRETTI, C.J. O Plano de Desenvolvimento da Educação. In: BERTUSSI, G.; OURIQUES, N. Anuário Educativo Brasileiro: visão retrospectiva. São Paulo: Cortez, 2011. p. 169-200.

NUN, J. La legitimidad democrática e los parecidos de família: notas preliminares. Punto de Vista, Buenos Aires, v. 10, n. 9, p. 30-44, 1987.

TRAVERSO, E. Il secolo armato: interpretare le violenze del Novecento. Milano: Giangiacomo Feltrinelli, 2012.

Recebido em 1ํㅡㄹ abril de 2013.

Aprovado em 17 de julho de 2013. 